\title{
A mechanistic investigation of the Suzuki polycondensation reaction using MS/MS methods
}

\author{
Michelle Y. C. Ting, Lars P. E. Yunker, Ian C. Chagunda, Katherine Hatlelid, Meghan Vieweg, \\ J. Scott McIndoe*
}

Department of Chemistry, University of Victoria, PO Box 1700 STN CSC, Victoria, BC V8W 2Y2, Canada.

Fax: +1 (250) 721-7147; Tel: +1 (250) 721-7181; E-mail: mcindoe@uvic.ca

\begin{abstract}
Understanding catalytic reactions is inherently difficult because not only is the catalyst the least abundant component in the mixture, but it also takes many different forms as the reaction proceeds. Precatalyst is converted into active catalyst, short-lived intermediates, resting states, and decomposition products. Polymerization catalysis is harder yet to study, because as the polymer grows the identities of these species change with every turnover as monomers are added to the chain. Modern mass spectrometric methods have proved to be up to the challenge, with multiple reaction monitoring (MRM) in conjunction with pressurized sample infusion (PSI) used to continuously probe all stages of the Suzuki polycondensation (SPC) reaction. Initiation, propagation, and termination steps were tracked in real time, and the outstanding sensitivity and low signal-to-noise of the approach has real promise with respect to the depth with which this reaction and others like it can be studied.
\end{abstract}

\section{Graphical Abstract}

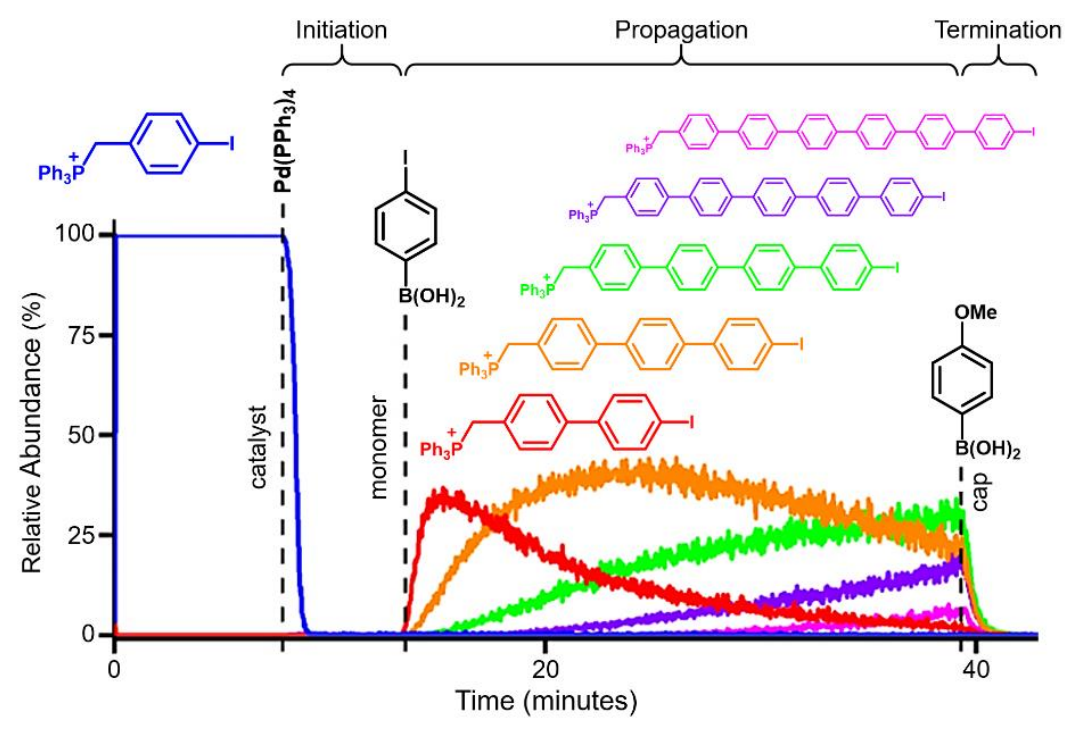




\section{Keywords}

Mass spectrometry, tandem mass spectrometry, multiple reaction monitoring, Suzuki polycondensation

\section{Introduction}

The Suzuki polycondensation reaction (SPC) ${ }^{1,2}$ employs palladium catalysts to produce conjugated polymers from difunctional monomers. Interest in the reaction is high thanks to the importance of these polymers to organic light emitting diode (OLED) display technologies. ${ }^{3,4}$ It largely employs the same catalysts and conditions as the Suzuki-Miyaura (SM) cross-coupling reaction ${ }^{5-8}$. The SM reaction is a well known palladium-catalysed cross-coupling reaction of organoboron compounds with organic halides. ${ }^{9}$ The high yields, reliability, and stereo- and regioselectivity make it one of the most widely used C-C bond forming reactions, with its discovery by Professor Akira Suzuki jointly earning the 2010 Nobel Prize in Chemistry. ${ }^{9,10}$ It proceeds in a cycle of three main steps as shown in Scheme $1 .^{10}$ The first step is the oxidative addition of an organic halide to a $\operatorname{Pd}(0)$ catalyst producing a $\mathrm{Pd}(\mathrm{II})$ intermediate. This is followed by the base-mediated transmetallation of the organoboron coupling partner to the $\mathrm{Pd}(\mathrm{II})$ intermediate, and finally the reductive elimination of the coupled product and regeneration of the $\operatorname{Pd}(0)$ catalyst. ${ }^{10}$

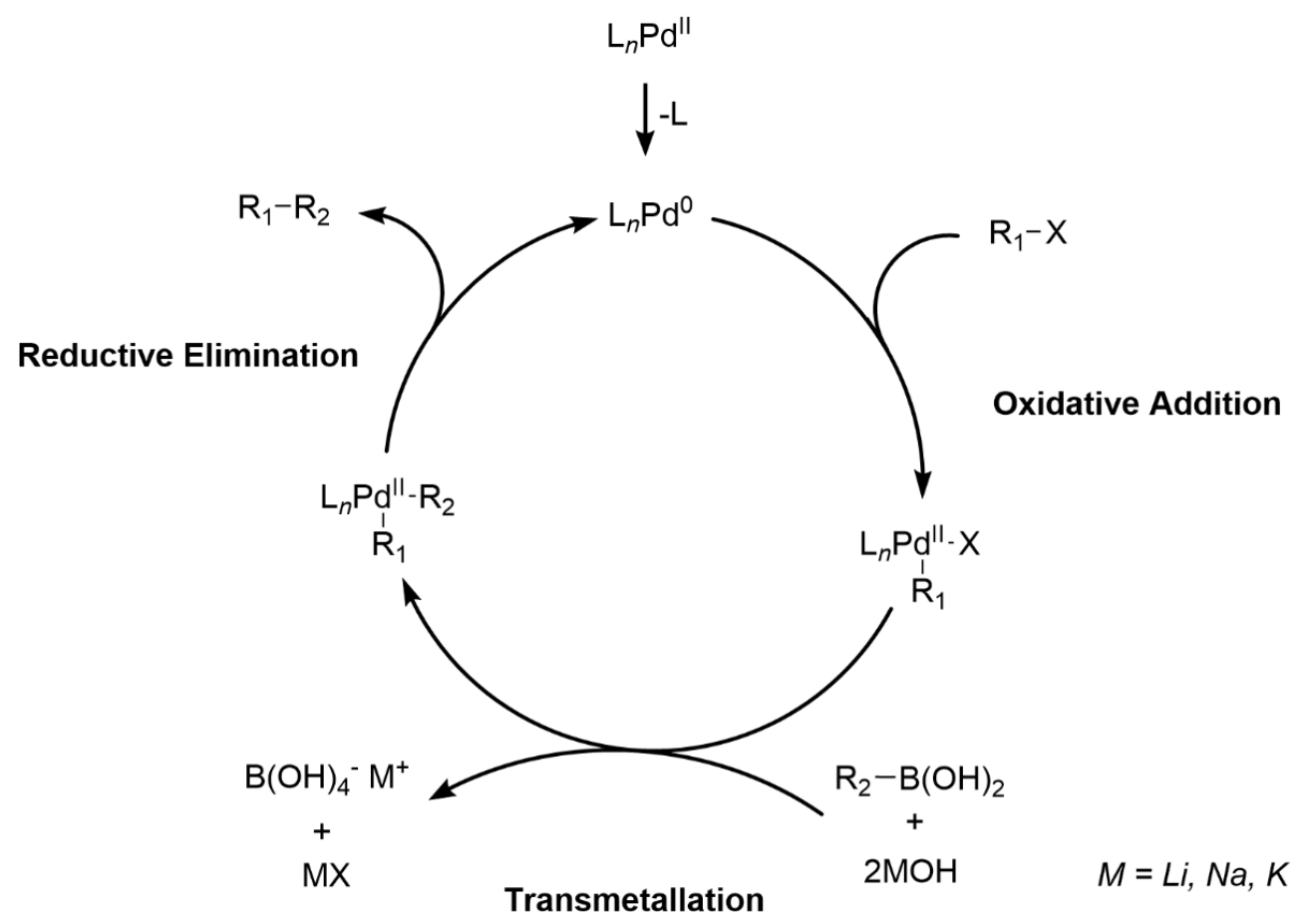

Scheme 1: Suzuki-Miyaura cross-coupling catalytic cycle. 
The SPC proceeds through a similar catalytic cycle as the Suzuki-Miyaura reaction, in a polymerforming process where difunctional aryl monomers connect to form repeating aromatic units. ${ }^{11}$ It can be conducted with AB-type monomers, i.e. an aryl halide and an aryl boronic acid (or ester) on the same monomer unit, or with $\mathrm{AA}$ and $\mathrm{BB}$-type monomers i.e. $\mathrm{X}$-aryl-X and $(\mathrm{HO})_{2} \mathrm{~B}$-aryl$\mathrm{B}(\mathrm{OH})_{2} \cdot{ }^{12-15}$ With $\mathrm{AB}$-type monomers, the polyarylenes obtained have repeat units of only one kind, while the AA and BB-type monomers can result in both homopolymers or polyarylenes with two kinds of alternating units. ${ }^{10,11}$

Mechanistic interest in the reaction stems from the importance of side reactions becoming magnified by their effect on polymer chain length and identity of end groups. Methods for analyzing the molecular weight distribution of the SPC are well-developed, as they are amenable to all the tools of the polymer chemist. ${ }^{16}$ But following the reaction on a molecular level is challenging, because the growing polymer chain repeatedly interacts with the metal catalyst, making the identity of the intermediates and resting states in the reaction change with every turnover. ${ }^{17}$ As such, an unusually powerful tool is required for studying the SPC.

Mass spectrometry is fast and extremely sensitive but studying the SPC poses special challenges: no two products or intermediates have the same molecular weight, and so whatever ion intensity one starts with at the beginning of the reaction gets dispersed across many new ions over the course of the reaction. As such, we expected that the normal approach of using conventional full-scan monitoring of the reaction was likely to have limited power to track all the species present, and planned to apply more sophisticated MS/MS methods as necessary. Triple quadrupole mass spectrometers use two quadrupole mass analyzers (MS1 and MS2) separated by a collision cell in which collision-induced dissociation (CID) can break ions into characteristic fragments. These instruments can perform in a variety of modes laid out in Figure 1. 
a)

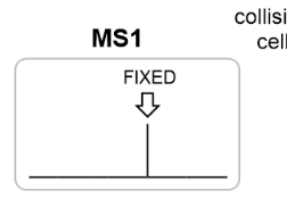

b)

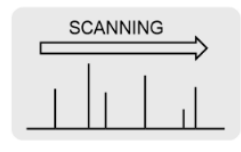

c)

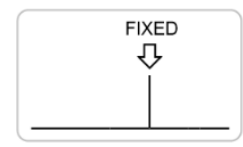

d)

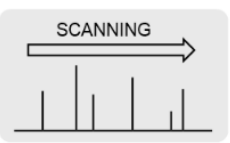

e)
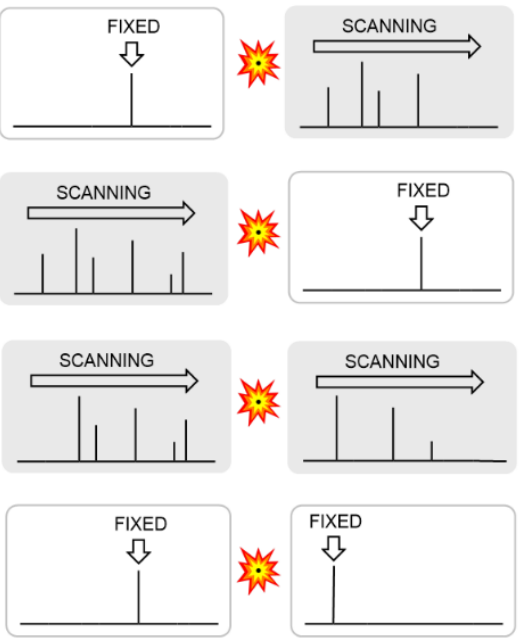

precurso

MS2

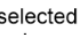

ion

full
scan

product
scan

scan

neutral

loss

scan

reaction monitoring

Figure 1: (a) one or many ions may be selected using a single quadrupole and their abundance monitored over time; (b) the entire mass-to-charge range of interested can be repetitively scanned in a full-scan mode; (c) an ion may be selected in MS1, fragmented in the collision cell, and the resulting product ions scanned in MS2; (d) MS1 may be set up to scan while MS2 is fixed, which allows only ions with a common fragment to arrive at the detector; (e) MS1 and MS2 are both scanned, with MS2 offset by a fixed value, which allows only ions with a common neutral loss to arrive at the detector; (f) MS1 is fixed at a value of a particular precursor ion, and MS2 is fixed at a value of a particular product ion, so only ions that have a specific $\mathrm{m} / \mathrm{z}$ and a specific product ion $\mathrm{m} / \mathrm{z}$ arrive at the detector. If this experiment cycles between multiple ions, this process is called multiple reaction monitoring (MRM).

ESI-MS is a well-established technique for mechanistic studies of organometallic catalytic processes. ${ }^{18-22}$ We have previously used real-time mass spectrometric methods to study the SuzukiMiyaura cross-coupling (SMC) reaction and various other transformations. ${ }^{23-29}$ Our standard method of real-time reaction analysis involves transporting a solution from the reaction flask to an electrospray ionization (ESI) mass spectrometer using pressurized sample infusion (PSI). ${ }^{30,31}$ ESIMS provides powerful real-time information, but the technique can observe only ions, not neutrals, so the entities of interest need to carry a charge (inherent, or appended synthetically in a location that does not affect the chemistry under investigation). ${ }^{32}$ Our strategy was to start the investigation of the SPC reaction using a charge-tagged aryl iodide $\left[p-\mathrm{IC}_{6} \mathrm{H}_{4}\left(\mathrm{CH}_{2}\right) \mathrm{PPh}_{3}\right]^{+}[\mathrm{PF} 6]-(\mathbf{1 0})$ to which we would add the $\mathrm{Pd}\left(\mathrm{PPh}_{3}\right)_{4}$ catalyst. The aryl iodide oxidatively adds to palladium $(0)$ readily, to install the charged tag at one of the termini of the planned polyphenylene oligomers. Addition of a difunctional monomer in the form of $p-\mathrm{IC}_{6} \mathrm{H}_{4} \mathrm{~B}(\mathrm{OH})_{2}$ would allow the reaction to turn over, 
adding a $-\left(\mathrm{C}_{6} \mathrm{H}_{4}\right)$ - unit to the oligomer with each cycle. The reaction could be terminated via addition of a monofunctional boronic acid, $p-\mathrm{MeOC}_{6} \mathrm{H}_{4} \mathrm{~B}(\mathrm{OH})_{2}$. The elaborated cycle is shown in Scheme 2 (termination step not shown). Note that the Scheme shows only the charged oligomers; following reductive elimination, the oligomer will compete with $p$ - $\mathrm{IC}_{6} \mathrm{H}_{4} \mathrm{~B}(\mathrm{OH})_{2}$ for oxidative addition to $\operatorname{Pd}(0)$. The resulting neutral oligomers are themselves competent as transmetallation partners, so they may end up with a charged terminus. It is clear that the kinetics of this reaction are likely to be very complicated, even in the absence of any competing side-reactions.

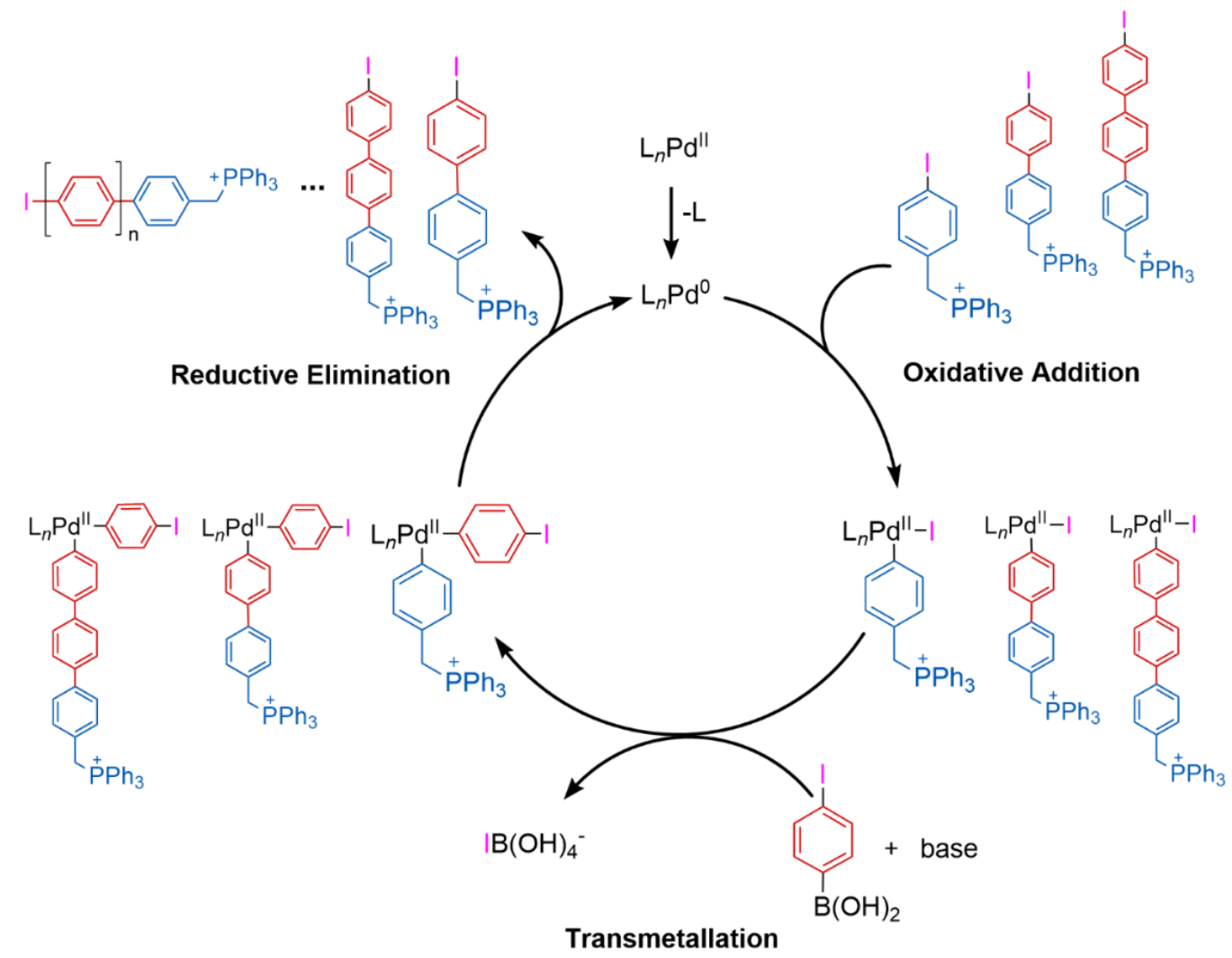

Scheme 2: Proposed SPC catalytic cycle where $\mathrm{L}=\mathrm{PPh}_{3}$, a phosphonium charged iodide tag, and an AB-type monomer $p$-iodophenylboronic acid were employed.

\section{Results and Discussion}

To get a sense of the reaction and the type of MS experiments that would be necessary to provide meaningful analyses, we probed the reaction using a variety of different modes.

\section{Full scan mode}


The simplest mode uses a single quadrupole to scan the $\mathrm{m} / \mathrm{z}$ range of interest to generate a mass spectrum of all ions being produced in the source, while the other quadrupole and collision cell simply pass all ions through. This is known as full scan mode (Figure 1b). Applying the full scan mode to the SPC, we used conditions analogous to those we previously employed to examine the Suzuki-Miyaura cross-coupling reaction (methanol solvent, $\mathrm{Pd}\left(\mathrm{PPh}_{3}\right)_{4}$ catalyst, $\mathrm{K}_{3} \mathrm{PO}_{4}$ base, charge-tagged aryl iodide) ${ }^{28}$ but instead of using a simple boronic acid as a cross-coupling partner, we used an AB-type monomer, $p$ - $\mathrm{IC}_{6} \mathrm{H}_{4} \mathrm{~B}(\mathrm{OH})_{2}$. We tracked the reaction using PSI-ESI-MS using the conditions described in the experimental section.

All traces were normalized to the total ion current (TIC) and presented in chronogram form in Figure 2. The numbering scheme employed gives all aryl iodide species of the type $\left[\mathrm{Ph}_{3} \mathrm{PCH}_{2} \mathrm{C}_{6} \mathrm{H}_{4}\left(\mathrm{C}_{6} \mathrm{H}_{4}\right)_{n} \mathrm{I}\right]^{+}$the label $\mathbf{1}_{n}$ (where $n=$ the number of aryl rings inserted). Similarly, palladium-containing intermediates of the form $\left[\left(\mathrm{PPh}_{3}\right)_{2} \mathrm{Pd}\left\{\left(\mathrm{C}_{6} \mathrm{H}_{4}\right)_{n} \mathrm{C}_{6} \mathrm{H}_{4} \mathrm{CH}_{2} \mathrm{PPh}_{3}\right\}\right]^{+}$are labelled $\boldsymbol{2}_{\boldsymbol{n}}$, and the capped product oligomers $\left[\mathrm{Ph}_{3} \mathrm{PCH}_{2} \mathrm{C}_{6} \mathrm{H}_{4}\left(\mathrm{C}_{6} \mathrm{H}_{4}\right)_{n}\left(\mathrm{C}_{6} \mathrm{H}_{4} \mathrm{OMe}\right)\right]^{+}$are labelled $\boldsymbol{3}_{\boldsymbol{n}}$. A stable signal for 10, the charge-tagged aryl iodide, was established and the $\mathrm{Pd}\left(\mathrm{PPh}_{3}\right)_{4}$ precatalyst added to the solution at 2 minutes causing a rapid decrease in the intensity of 10, and an increase in intensity of 20. The half-life of this reaction was faster than the time it takes for the solution to move from the reaction vessel to the mass spectrometer, i.e. $t_{1 / 2}<20 \mathrm{~s}$. When the AB monomer substrate was added at 20 minutes, a decrease in intensity of $\mathbf{2 0}$ was observed and species corresponding to 1-6 and 22-4 appeared sequentially, indicating that reaction turnover had occurred. Little change to the speciation occurred beyond 40 minutes, so a capping agent, $\mathrm{PhB}(\mathrm{OH})_{2}$, was added at 44 minutes and 30-4 were observed. SPC reactions are typically left for hours or overnight to react. ${ }^{34-37}$ Under the conditions used, the reaction appears to have turned over 0-6 times in the 80-minute observation period. A summation of all mass spectra collected over these 80 minutes of reaction time is shown in Table S1 of the Supporting Information. 


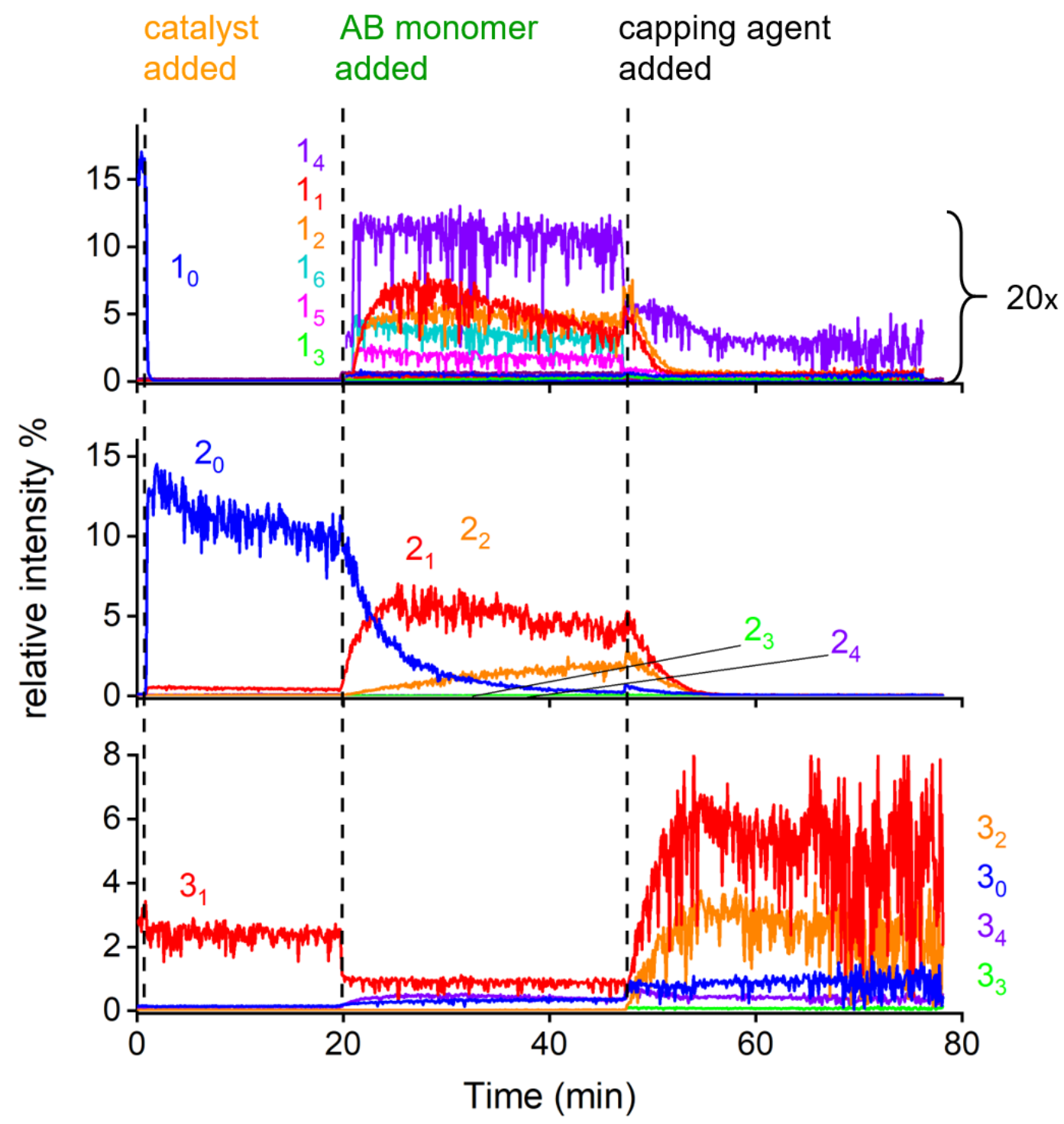

Figure 2. The normalized PSI-ESI-MS full scan chronogram of the SPC. Aryl iodide species are label as $1_{n}$, intermediates as $2_{n}$, and capped oligomer products as $3_{n}(n=1-6)$. The $\mathrm{Pd}\left(\mathrm{PPh}_{3}\right)_{4}$ precatalyst, $\mathrm{AB}$ monomer $p-(\mathrm{OH})_{2} \mathrm{BC}_{6} \mathrm{H}_{4} \mathrm{l}$ and the end-capping agent $\mathrm{PhB}(\mathrm{OH})_{2}$ was added to the reaction solution at 2 minutes, 20 minutes, and 44 minutes as indicated with dotted lines.

The full scan mode chronogram shows the general flow of reactants, intermediates, and products through this cycle as expected, though with considerable limitations. The high signal noise makes the traces barely intelligible, with some of the signals lost in the baseline and requiring multiplication by a factor of 20 to be observed at all. Some species also appeared to be present before it was physically possible for them to be there as the corresponding reagent was not injected into the reaction mixture until later. For example, $\mathbf{2}_{\mathbf{1 - 2}}$ showed a low intensity before the AB monomer was added, and $\mathbf{3}_{1}$ is very prominent, appearing at the beginning of the reaction at 0 minutes. Such behavior was almost certainly due to the presence of conflating species and 
contaminants with the same $\mathrm{m} / \mathrm{z}$ as the catalytic species of interest. There are also several unassigned mass peaks in the mass spectrum, which are likely to be cesium carbonate aggregates, trace impurities from previous analyses, species formed from methanolysis and contaminants from the septa when reagents were injected into the reaction mixture. ${ }^{38}$ Nonetheless, it was clear that the chemistry could be studied despite the fact the intermediates and products changed in $\mathrm{m} / \mathrm{z}$ with every turnover, though the methodology needed improvement. For that we attempted to narrow the scope of species analyzed using the selected ion recording (SIR) mode.

\section{Selected ion recording $(S I R)$}

With the known target species in hand, we could start applying different methods to get more reliable, selective, and sensitive chronograms of the catalytic reaction. The first method we tried was selected ion recording (SIR), an approach that can be employed by any scanning MS instrument. Instead of scanning the entire mass range, only the ions of interest are targeted. The most intense peak of a particular isotope envelope, or the most intense peak unaffected by overlap with another species, can be selected, and the amount of time each species is dwelled upon can be customized. Also, the mass spectrum of SIR experiment does not show the isotopic pattern, just the selected mass peak(s) and their intensity, further simplifying the spectrum produced.

For this experiment, the $\mathrm{m} / \mathrm{z}$ ratio of each catalytic species was calculated and input into the mass spectrometer. The dwell time of the Pd-containing species was set to be longer than that of the aryl iodide and oligomeric product species to increase the $\mathrm{S}: \mathrm{N}$ ratio. The amount of $\mathrm{AB}$ monomer was adjusted to 6 equivalents instead of 12 since species with $n>5$ were not observed. All other reaction conditions and mass spectrometer settings remained the same in order to compare results with the full scan chronogram. The normalized chronogram of each set of species is shown in Figure 3 following the same sequence of substrate addition as with the full scan chronogram. 


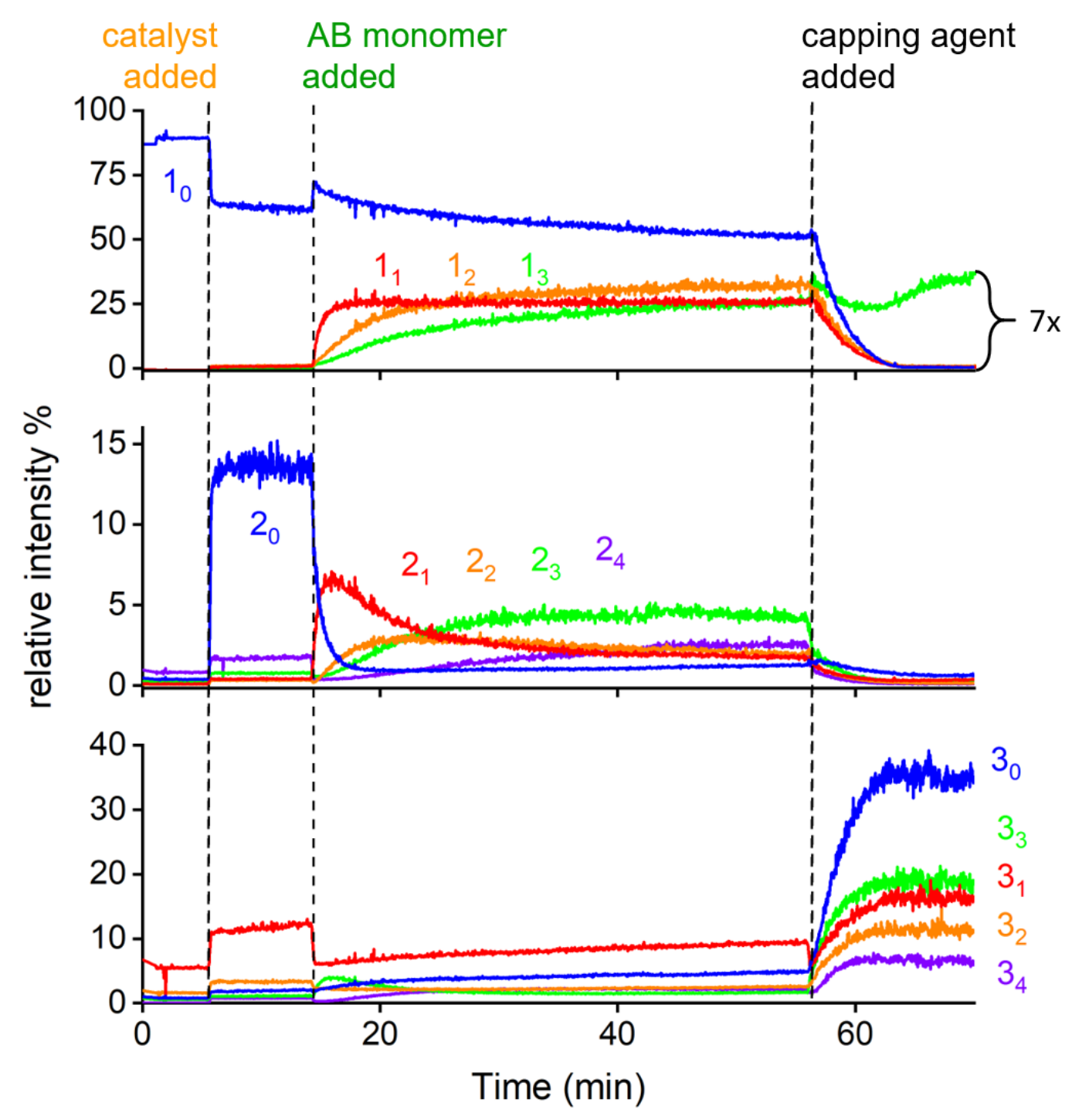

Figure 3: The normalized ESI-MS SIR chronogram of the SPC showing the relative intensity of aryl iodide species label as $1_{n}$, intermediates as $2 n$, and the end-capped oligomer products as $3_{n}(n=0-4)$. The $\mathrm{Pd}\left(\mathrm{PPh}_{3}\right)_{4}$ precatalyst, $\mathrm{AB}$ monomer $p-(\mathrm{OH})_{2} \mathrm{BC}_{6} \mathrm{H}_{4}$ l, and the end-capping agent $\mathrm{C}_{6} \mathrm{H}_{4} \mathrm{~B}(\mathrm{OH})_{2}$ was added to the reaction solution at 5 minutes, 14 minutes, and 57 minutes indicated in dotted lines respectively.

The SIR chronogram showed significant improvements in the traces of all species and appeared cleaner and more intelligible. Low intensity species observed in a full scan chromatogram were amplified in an SIR chromatogram by adjusting the dwell time upwards, with additional baseline multiplication by a factor of seven. Upon AB monomer addition, 21-4 showed a significant increase in relative intensity and decrease when the capping agent was added to the reaction mixture. Why the palladium-containing species $\mathbf{2} \mathbf{n}$ behave better than the aryl iodides $\mathbf{1} \mathbf{n}$ in this respect may be due to their relative $m / z$ values - low mass ions are more likely to experience adventitious overlap than higher mass ions. Aside from the $\mathbf{2} \mathbf{n}$ intermediates, we were also able to observe the capped 
oligomers 30-4 when the capping agent was added at 57 minutes, which in contrast showed very low intensity in the full scan chromatogram. However, their behavior is clearly non-physical. The capped oligomers $\mathbf{3}_{\mathbf{n}}$ appeared long before the capping reagent itself was added, and similar problematic behavior was seen for the $\mathbf{2}_{\mathrm{n}}$ species appearing prior to $\mathrm{AB}$ monomer addition. This presents the challenge of how to differentiate when a trace is coming from background noise, or overlapping species, or from part of the catalytic cycle.

\section{Neutral loss mode}

To help solve the problem of coincidental overlap, we turned to MS/MS methods. A product ion scan is the most common MS/MS experiment. A precursor ion is selected in MS1 and undergoes collision-induced dissociation to produce a product ion and a neutral fragment. The product ion is then detected in MS2 (Figure 1c). Product ion scans were performed on 10-4, 20-1, and 30-4 which revealed that all ions under study decompose in the gas phase under CID conditions to lose triphenylphosphine $\left(\mathrm{PPh}_{3}\right.$; see supporting information Figures SI 1-6). We optimised the collision voltage for maximum abundance of the product ion in each case, with 2 n ions needing $15-20 \mathrm{~V}$ lower than that required for $\mathbf{1}_{\boldsymbol{n}}$ and $\mathbf{3}_{\boldsymbol{n}}(30-35 \mathrm{~V}) . \mathrm{PPh}_{3}$ (an L-type ligand) is readily lost from palladium through a simple ligand dissociation, hence the lower voltage required compared to decomposition of the triphenylphosphonium tag. L-type ligands tend to dissociate first because they are stable as free entities, while X-type ligands take more energy for homolytic dissociation due to the requirement of radical formation.. ${ }^{26,28,39,40}$

The product ion spectra of the $\mathbf{2}_{\boldsymbol{n}}$ ions were especially interesting because there is some structural ambiguity in all $\boldsymbol{2}_{\boldsymbol{n}}$ ions except $\mathbf{2}_{0}$. $\mathbf{2}_{0}$ must be $\left[\left(\mathrm{Ph}_{3} \mathrm{P}\right)_{2} \mathrm{Pd}\left(\mathrm{C}_{6} \mathrm{H}_{4} \mathrm{CH}_{2} \mathrm{PPh}_{3}\right)\right]^{+}$, the product of oxidative addition of $\mathbf{1 0}$ to $\mathrm{Pd}\left(\mathrm{PPh}_{3}\right)_{n}$. In contrast $\mathbf{2 1}$ could be analogous to $\mathbf{2 0}$ i.e. $\left[\left(\mathrm{Ph}_{3} \mathrm{P}\right)_{2} \mathrm{Pd}\left\{\left(\mathrm{C}_{6} \mathrm{H}_{4}\right) \mathrm{C}_{6} \mathrm{H}_{4} \mathrm{CH}_{2} \mathrm{PPh}_{3}\right\}\right]^{+}$or the diaryl isomer $\left[\left(\mathrm{Ph}_{3} \mathrm{P}\right)_{2} \mathrm{Pd}\left(\mathrm{C}_{6} \mathrm{H}_{4} \mathrm{CH}_{2} \mathrm{PPh}_{3}\right)\left(\mathrm{C}_{6} \mathrm{H}_{4} \mathrm{I}\right)\right]^{+}$ that has not yet undergone reductive elimination. MS/MS studies can help tease these possibilities apart because it is well-established that species that undergo solution phase reductive elimination are prone to the same behavior in the gas phase. ${ }^{41,42}$ Accordingly, we looked closely at the product ion spectrum (supporting information Figure SI 5): any signs of reductive elimination of a biphenyl moiety would point to the presence of the diaryl isomer. This spectrum was heavily dominated by $\mathrm{PPh}_{3}$ loss, indicating that the species at $\mathrm{m} / z 1185$ was the oxidative addition product rather than the diaryl species. However, there was a small amount of a species with $m / z 555$, corresponding to the reductive elimination of $\left[\mathrm{Ph}_{3} \mathrm{PCH}_{2} \mathrm{C}_{6} \mathrm{H}_{4} \mathrm{C}_{6} \mathrm{H}_{4} \mathrm{I}\right]^{+}$, as well as some other species pointing to phosphine scrambling. These included $m / z \quad 613, \quad\left[\mathrm{Ph}_{3} \mathrm{PCH}_{2} \mathrm{C}_{6} \mathrm{H}_{4} \mathrm{C}_{6} \mathrm{H}_{4} \mathrm{PPh}_{2}\right]^{+}, \quad m / z \quad 429$ $\left[\mathrm{Ph}_{3} \mathrm{PCH}_{2} \mathrm{C}_{6} \mathrm{H}_{4} \mathrm{Ph}\right]^{+}$, and $\mathrm{m} / z 339\left[\mathrm{PPh}_{4}\right]^{+}$. Phosphine scrambling is a notable side reaction in palladium-cross coupling reaction, ${ }^{4-46}$ involving the exchange of aryl groups on palladium with aryl groups on phosphorus. It is problematic in the context of the SPC, as it is a termination step in the polymerization. The proposed phosphine scrambling pathway is summarized in Scheme SI1). 
The results of the MS/MS analysis on $\mathbf{2}_{\mathbf{n}}$ species helped explain the peculiar behavior of the capped oligomers $3_{0-4}$ in the full scan and SIR chromatogram. We used phenylboronic acid, $\mathrm{C}_{6} \mathrm{H}_{4} \mathrm{~B}(\mathrm{OH})_{2}$ as the capping agent for the SPC and found that the predicted $\mathrm{m} / z$ ratio of the capped oligomers would have the same $m / z$ ratio as the phosphine scrambling products. Each tandem mass spectrum of 21-3 showed low abundance signals at $m / z 429,505,581$ that are assigned as aryl phosphine scrambling products through the transmetallation species pathway, $\operatorname{Ar}^{+}\left(\mathrm{C}_{6} \mathrm{H}_{4}\right) \mathrm{H}, \mathrm{Ar}^{+}\left(\mathrm{C}_{6} \mathrm{H}_{4}\right)_{2} \mathrm{H}$ and $\operatorname{Ar}^{+}\left(\mathrm{C}_{6} \mathrm{H}_{4}\right)_{3} \mathrm{H}$. It would therefore be possible to observe species with $\mathrm{m} / z$ ratios matching $3_{0-4}$ prior to the addition of the capping agent in the full scan and SIR chronograms. Their appearance indicated that there is a substantial amount of phosphine scrambling going on, and that we should not consider the behaviour of $\mathbf{3}_{\mathbf{0}-4}$ as background noise or adventitious overlapping species. We addressed this complication by switching to a different capping agent, methoxyphenylboronic acid $\mathrm{MeOC}_{6} \mathrm{H}_{4} \mathrm{~B}(\mathrm{OH})_{2}$, with the new capped products $\left[\mathrm{Ph}_{3} \mathrm{PCH}_{2} \mathrm{C}_{6} \mathrm{H}_{4}\left(\mathrm{C}_{6} \mathrm{H}_{4}\right)_{n} \mathrm{OMe}\right]^{+}\left(\mathbf{4}_{\mathbf{n}}\right)$ having different masses from the phosphine scrambling products (+30 Da, see supporting information Table S1). We further modified the product ion scan mode to using the neutral scan mode.

Because all species decompose by the same fragmentation pathway, $\mathrm{PPh}_{3}$ elimination, setting up a neutral loss scan was straightforward. In a neutral loss scan, both MS1 and MS2 are scanning together but MS2 scans with a mass offset equivalent to the neutral loss of interest. All ions are allowed to pass through MS1 to undergo the CID process, but only ions that lose a common neutral fragment after the CID process are detected in MS2 (Figure 1e). Moreover, neutral loss scan enables two or more functions set up with different collision energy to interweave in the same scan to obtain ions that give out different fragmentation pattern at different collision energy. The data is collected into one single raw file with two (or more) functions with two mass spectra and two chromatograms and each mass spectrum displays ion peak(s) that is detected at the specific collision energy. This scan mode is especially beneficial to study the SPC as it increases the signalto-noise ratio by excluding ions that do not lose a $\mathrm{PPh}_{3}$ fragment (262 Da), but bear the same $\mathrm{m} / \mathrm{z}$ ratio as the $\mathbf{1}_{\mathbf{n}}, \mathbf{2}_{\mathbf{n}}$, and $\mathbf{4}_{\mathbf{n}}$ species of interests. Since the product ion scan experiments revealed that each series did not exhibit the same fragmentation at the same collision energy, it was possible to set up one experiment with multiple functions of neutral loss scans to detect ions of all series of interest at their optimal collision energy.

The normalized chronogram of the neutral loss scan is shown in Figure 4 and all reaction conditions remained the same as with full scan and SIR experiments. A multiplier was not necessary, as each trace showed an observable relative intensity. The aryl iodides 10-4 and Pdcontaining species 20-4 exhibited a sequential increase in intensity much like the full scan and the SIR chronogram, and a relatively stable sequential increase and decrease in intensity during catalyst addition at 12 minutes and $\mathrm{AB}$ monomer addition at 18 minutes. The methoxyphenylboronic acid capping agent was added at 36 minutes, with both 10-4 and 20-4 showing gradual decreases in their relative intensity and $\mathbf{4 0 - 4}$ showing increases in their relative intensity. The neutral loss scan chronogram showed a further reduction of chemical noise in 
comparison to the full scan and SIR chronograms. It has also eliminated what appears to be a significant problem with the 1n species, which in SIR mode maintain significant intensity even after the addition of the precatalyst $\mathrm{Pd}\left(\mathrm{PPh}_{3}\right)_{4}$. The $1_{0}$ species ought to be very reactive towards oxidative addition, and the neutral loss scan confirms this, as it drops in intensity rapidly after addition of the precatalyst.

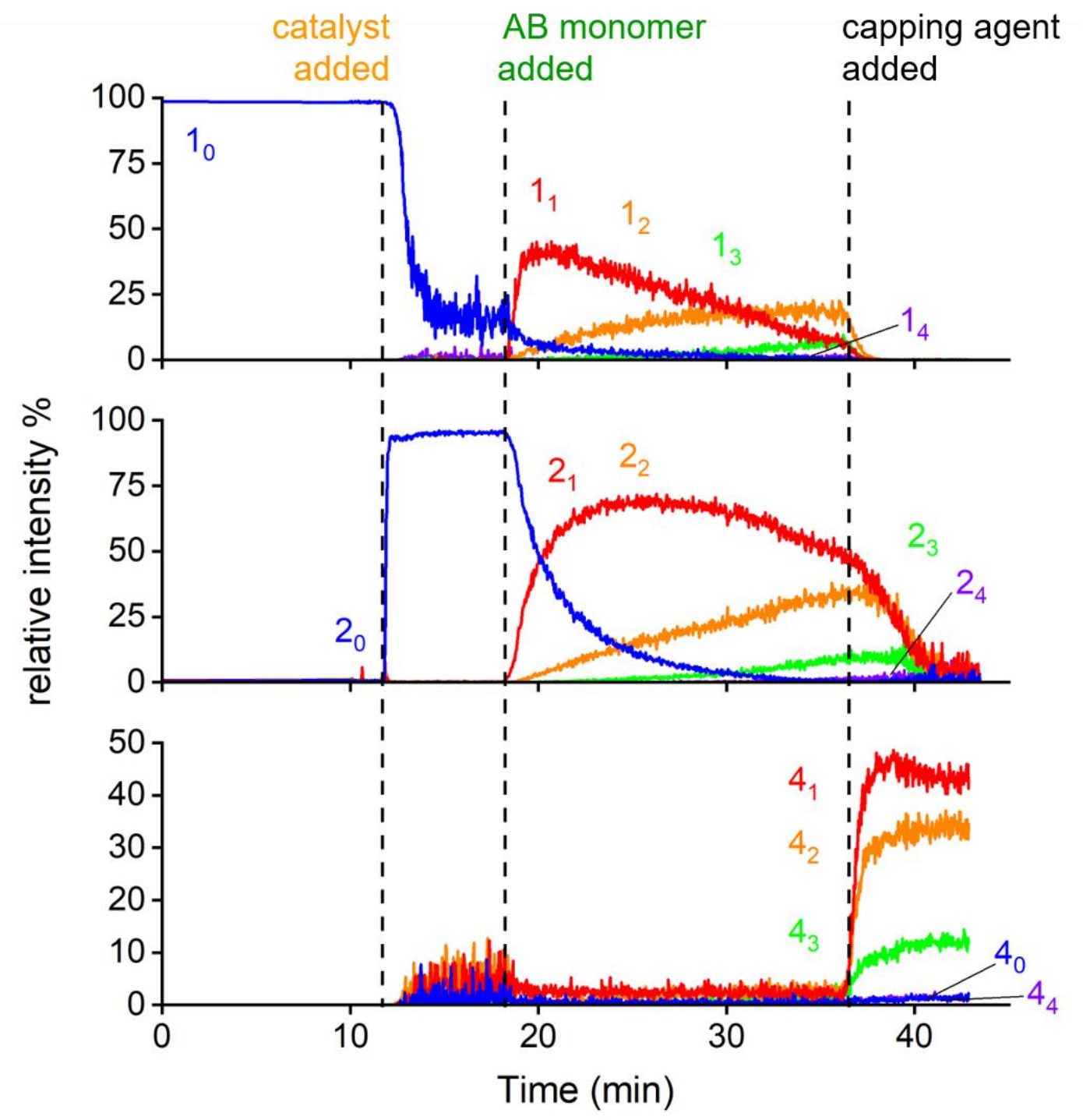

Figure 4: The normalized PSI-ESI-MS neutral loss scan chronogram of the SPC showing the relative intensity of aryl iodide species label as $1_{n}$, intermediates as $2_{n}$, and new capped oligomer products as $4 n$ $(n=0-4)$. The precatalyst $\mathrm{Pd}\left(\mathrm{PPh}_{3}\right)_{4}, \mathrm{AB}$ monomer $p-(\mathrm{OH})_{2} \mathrm{BC}_{6} \mathrm{H}_{4} l$ and the end-capping agent $\mathrm{MeOC}_{6} \mathrm{H}_{4} \mathrm{~B}(\mathrm{OH})_{2}$ was added at 12 minutes, 18 minutes, and 36 minutes indicated with dotted lines.

Unlike SIR, which increases signal but does nothing about noise and overlap ion peaks, the neutral loss scans are useful for reducing noise and overlapping species but do not help in increasing the signal intensity. The signal intensity increases emerge by ensuring the scanning instrument spends 
its time focused only on the peaks of interest. The experimental results of the neutral loss scan are satisfactory in terms of sensitivity and selectivity of the SPC monitoring, but triple quadrupole mass spectrometers still have another mode to exploit: multiple reaction monitoring (MRM).

\section{Multiple reaction monitoring}

MRM is a rapid, highly sensitive and selective screening method used for monitoring one or multiple specific ion transition(s). ${ }^{47-51}$ The collision energy is optimized to produce a diagnostic charged fragment of that ion (already established from the product ion scan experiments). Many MRM experiments can be compiled together into one experiment to measure many specific ions in a complex mixture. It is crucial to obtain precursor ion and product ion information along with ionization and fragmentation parameters prior to an MRM experiment. MRM methods can then be easily set up by inputting the precursor and product ion $\mathrm{m} / \mathrm{z}$, the collision voltage, and the dwell time and span of the peak. This mode provided the best and most chemically sensible data of all the approaches. Similar to an SIR experiment, MRM does not generate a mass spectrum with isotopic patterns but a signal peak at the pre-selected $\mathrm{m} / \mathrm{z}$ ratio, typically chosen to be the most intense signal in the isotopomer envelope, with the relative intensity of this peak shown in the extracted ion chromatogram.

The MRM chronogram of the SPC reaction is shown in Figure 5. At time 0, 10 can be observed and was consumed at the addition of the precatalyst, $\mathrm{Pd}\left(\mathrm{PPh}_{3}\right)_{4}$ at 8 minutes and accompanied by the appearance of 20 . When the $\mathrm{AB}$ monomer was added at 12 minutes, a decrease in intensity of 20 was observed and species corresponding to 1-4 and 21-4 appeared sequentially, indicating that reaction turnover had occurred. The capping agent, $\mathrm{MeOC}_{6} \mathrm{H}_{4} \mathrm{~B}(\mathrm{OH})_{2}$, was added at 38 minutes and all the $\mathbf{4}_{0-4}$ products were produced rapidly. It was also noted that the relative intensity of $\mathbf{4}_{\mathbf{3}, \mathbf{4}}$ were shown to decrease right after its appearance in this experiment. Overall, the result of the MRM appears to be very clean, species of interest no longer appeared at the beginning of the chronogram, meaning that species (apart from 10) that appear at 0 mins in the full scan and SIR results were likely to be $\mathrm{S}: \mathrm{N}$ artefacts or contaminants. 


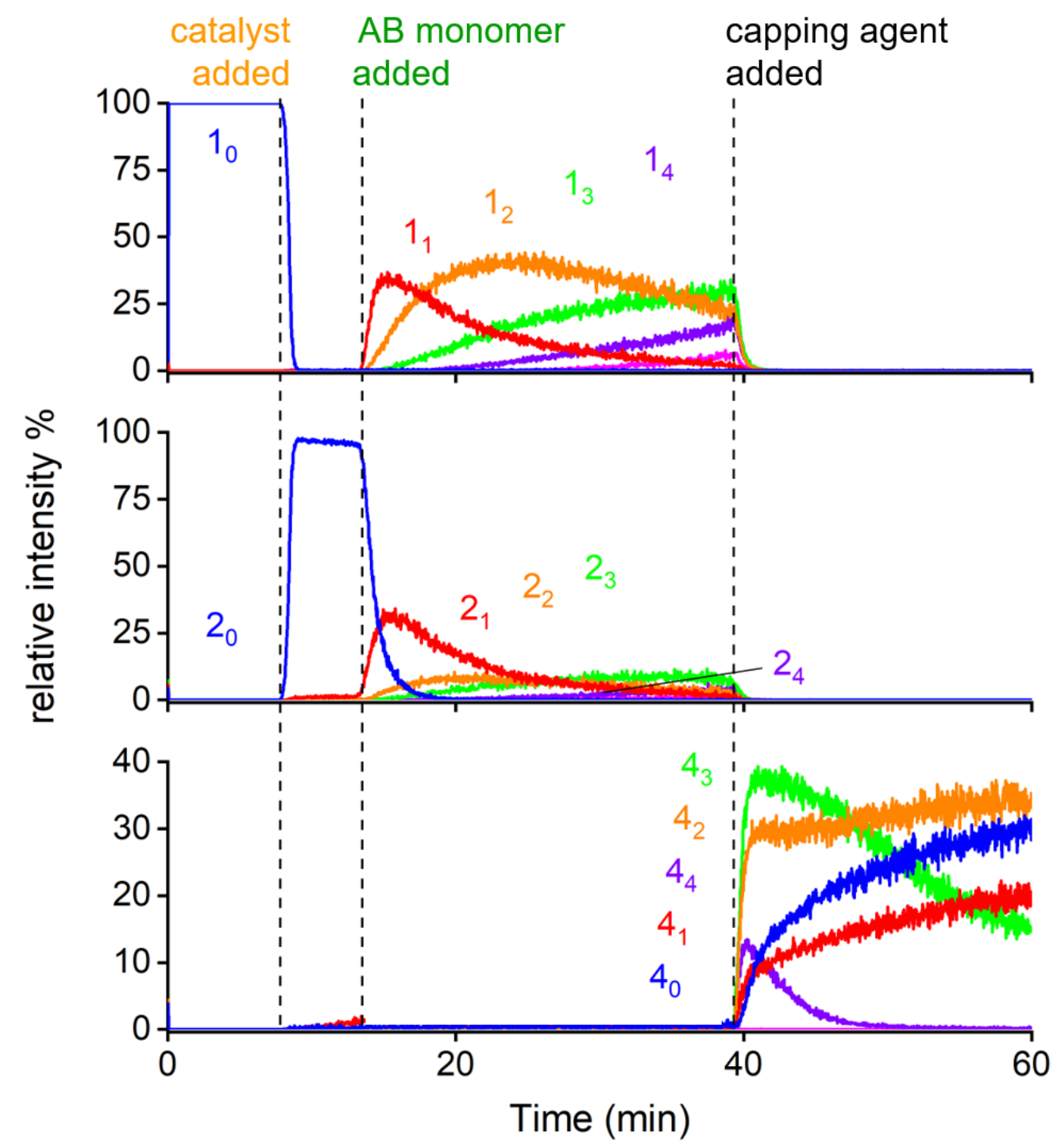

Figure 5: The normalized PSI-ESI-MS MRM chronogram of the SPC showing the relative intensity of aryl iodide species label as $1_{n}$, intermediates as $2_{n}$, and capped oligomer products as $4_{n}(n=0-4)$. The precatalyst $\mathrm{Pd}\left(\mathrm{PPh}_{3}\right)_{4}, \mathrm{AB}$ monomer $p-(\mathrm{OH})_{2} \mathrm{BC}_{6} \mathrm{H}_{4} \mathrm{l}$ and the end-capping agent $\mathrm{MeOC}_{6} \mathrm{H}_{4} \mathrm{~B}(\mathrm{OH})_{2}$ was added at 8 minutes, 12 minutes, and 38 minutes indicated in dotted lines.

What does the MRM data tell us about the reaction? First, it needs to be appreciated that the catalytic cycle shown in previous chronograms using full scan, SIR, and neutral loss scan is not the complete story. After reductive elimination of each new biaryl compound, the catalyst has several available options: it can oxidatively add to the charge-tagged polyaryl iodide 1n>0, the difunctional $\mathrm{AB}$ monomer $\mathrm{IC}_{6} \mathrm{H}_{4} \mathrm{~B}(\mathrm{OH})_{2}$, or an untagged difunctional polyaryl iodide, $\mathrm{I}\left(\mathrm{C}_{6} \mathrm{H}_{4}\right)_{n} \mathrm{~B}(\mathrm{OH})_{2}$. Only one of these is charged, and so an appreciable chunk of the reactive species goes undetected. It is also possible that the transmetallation can be between a tagged species and a difunctional polyaryl species of the type $(\mathrm{HO})_{2} \mathrm{~B}\left(\mathrm{C}_{6} \mathrm{H}_{4}\right)_{n} \mathrm{I}$. 
A further outstanding question remains concerning the $2_{\mathbf{n}}$ species. There is some ambiguity in the composition of these species, although we can be certain they are of the general formula $\left[\left(\mathrm{Ph}_{3} \mathrm{P}\right)_{2} \mathrm{Pd}\left\{\left(\mathrm{C}_{6} \mathrm{H}_{4}\right)_{n} \mathrm{CH}_{2} \mathrm{PPh}_{3}\right\}\right]^{+}$. There are four options: the two sets of cis and trans isomers for each of $\left[\left[\left(\mathrm{Ph}_{3} \mathrm{P}\right)_{2} \mathrm{Pd}\left\{\left(\mathrm{C}_{6} \mathrm{H}_{4}\right)_{n} \mathrm{CH}_{2} \mathrm{PPh}_{3}\right\}\right]^{+}\right.$, where the ligands are aryl and iodide, and $\left[\left(\mathrm{Ph}_{3} \mathrm{P}\right)_{2} \mathrm{Pd}\left\{\left(\mathrm{C}_{6} \mathrm{H}_{4}\right)_{n} \mathrm{CH}_{2} \mathrm{PPh}_{3}\right\}\left(\mathrm{C}_{6} \mathrm{H}_{4}\right)_{n}\right]^{+}$, where the ligands are both aryl. MS/MS examination can assist with untangling the ambiguity, since bis(aryl) palladium species are prone to reductive elimination of a biaryl species, ${ }^{41,52}$ whereas an aryl palladium iodide is not. However, the product ion scan analysis of each Pd-containing species showed only a low intensity of the biaryl species $\left(\mathrm{Ar}^{+} \mathrm{C}_{6} \mathrm{H}_{4} \mathrm{OMe}\right)_{1-4}$. The rest of the MS/MS analysis of the gas phase ions revealed a series of fragments, suggesting that more than one fragmentation pathway was behind the production of these product ions, pointing to the aryl phosphine scrambling reaction (see supporting information Scheme S1). ${ }^{43-46}$ This aryl phosphine scrambling is a notorious side reaction that takes place in SMC and more so in SPC because the polyaryl chain length can be halted. ${ }^{53}$ The fact that the $\mathbf{3}_{\mathbf{n}}$ species appeared right after $\mathrm{AB}$ monomer addition observed in the full scan and SIR chronogram is likely an indication of the phosphine scrambling taking place in the reaction solution. We can be confident about this after switching to a different capping agent and observing the relative intensity of the $\mathbf{4}_{\mathbf{n}}$ species that made physical sense, i.e. they did not appear before addition of the capping reagent.

The formation of the oligomer product series $4 \mathbf{n}$ studied in each method were shown to have a dramatic increase as soon as the addition of capping agent terminated the ongoing catalytic cycle, suggesting that SPC is a step-growth polymerization. This observation is consistent with the SMC mechanism and the SPC literature as it would be impossible to observe the catalytic species (12-4 and 22-4) at the same time had the reaction proceeded in a chain-growth fashion. The behaviour of $\mathbf{4 3}$ and $\mathbf{4} 4$ were intriguing as the relative intensity rapidly increased and decreased. Because this behavior was more pronounced for $\mathbf{4} \mathbf{4}$ than for $\mathbf{4 3}$, it is most likely due to low solubility of the higher oligomers.

\section{Experimental}

Reagents were purchased from Sigma-Aldrich and were used without further purification. Methanol (HPLC grade) was distilled from calcium hydride before every use. Gases were purchased from Airgas (Calgary, Canada) and used without further purification. All experiments and reagents were performed under nitrogen atmosphere using standard Schlenk and glovebox techniques. All mass spectra were collected by a Waters Acquity Triple Quadrupole Mass spectrometer equipped with a Z-Spray pneumatically assisted electrospray ionization source in the positive ion mode. 
Synthesis of the charged tag $\left[\mathrm{Ph}_{3} \mathrm{PCH}_{2} \mathrm{C}_{6} \mathrm{H}_{4} \mathrm{I}^{+}\left[\mathrm{PF}_{6}\right]^{-}\left(\mathbf{1}_{\mathbf{0}}\right)\right.$ was previously reported. ${ }^{42}$ Stock solutions of 10, 4-iodophenylboronic acid, 4-methoxyphenylboronic acid, and phenylboronic acid were prepared in $\mathrm{MeOH}$ at concentrations of $0.5,3.0,1.0$, and $1.0 \mathrm{mmolL}^{-1}$ respectively. Tetrakistriphenylphosphine palladium(0) $(11.5 \mathrm{mg})$ was prepared in $4 \mathrm{~mL}$ of THF for each experiment. All solutions were kept in a glovebox until ready for use.

All reactions were monitored using PSI-ESI-MS under the following conditions. Methanol ( $20 \mathrm{ml})$, stirrer bar, and $\mathrm{K}_{3} \mathrm{PO}_{4}$ base ( $2 \mathrm{mg}, 9 \mu \mathrm{mol}$ ) was added to the Schlenk flask at a bath temperature of $40{ }^{\circ} \mathrm{C}$. The charged aryl iodide, $\left[\mathrm{Ph}_{3} \mathrm{PCH}_{2} \mathrm{C}_{6} \mathrm{H}_{4} \mathrm{I}\right]^{+}\left[\mathrm{PF}_{6}\right]^{-}\left(\mathbf{1}_{0}, 0.4 \mathrm{~mL}\right.$ of the $0.5 \mathrm{mmolL}^{-1}$ stock solution, $0.2 \mu \mathrm{mol}$ ) was added to the flask by syringe through a septum. After a short period ( 10 minutes), a solution of the $\mathrm{Pd}\left(\mathrm{PPh}_{3}\right)_{4}$ precatalyst $(11.5 \mathrm{mg}, 10 \mu \mathrm{mol}$ in $4 \mathrm{ml}$ of THF) was added until all of $\mathbf{1}_{0}$ was consumed. After about 10 minutes, the $\mathrm{AB}$ monomer, $\mathrm{IC}_{6} \mathrm{H}_{4} \mathrm{~B}(\mathrm{OH})_{2}(0.8 \mathrm{ml}$ of the $3.0 \mathrm{mmolL}^{-1}$ stock solution, $2.4 \mu \mathrm{mol}$ ) was added by syringe. The reaction was allowed to proceed for about 40 minutes before the capping reagent, $\mathrm{C}_{6} \mathrm{H}_{5} \mathrm{~B}(\mathrm{OH})_{2}$ or $\mathrm{MeOC}_{6} \mathrm{H}_{4} \mathrm{~B}(\mathrm{OH})_{2}(1.0$ $\mathrm{mL}$ of the $1.0 \mathrm{mmolL}^{-1}$ stock solution, $\left.1.0 \mu \mathrm{mol}\right)$ was added by syringe. Data collection continued for a further 20 minutes.

\section{Conclusions}

The application of PSI-ESI-MS under our experimental conditions revealed that the palladium intermediates in the Suzuki polycondensation catalytic cycle potentially undergo competing pathway between transmetallation and aryl-phosphine ligand scrambling. We expected to observe a reductive elimination pathway from the Pd intermediates when subjected to MS/MS analysis. Instead, CID data revealed the involvement of the aryl-phosphine ligand scrambling in the Pd intermediates. This generated a number of species including iodobenzene, $\mathrm{C}_{6} \mathrm{H}_{4} \mathrm{I}$, aryl-phosphines $\mathrm{Ph}_{3} \mathrm{P}^{+} \mathrm{CH}_{2}\left(\mathrm{C}_{6} \mathrm{H}_{4}\right)_{n}$, and $\mathrm{Pd}$-phosphines $\left[\mathrm{Pd}\left\{\left(\mathrm{Ph}_{3} \mathrm{P}^{+} \mathrm{CH}_{2}\left(\mathrm{C}_{6} \mathrm{H}_{4}\right)_{n}\right) \mathrm{P}\left(\mathrm{Ph}_{2}\right)\right\}\right]$ and $\left[\mathrm{Pd}-\mathrm{P}\left(\mathrm{Ph}_{2}\right)\left(\mathrm{C}_{6} \mathrm{H}_{4} \mathrm{I}\right)\right]$. Product ions with the charged phosphonium tag were well observed in the CID mass spectra. The ligand-scrambling phenomenon may attribute to the incomplete conversion of the observed oligomer products as seen in the chronogram data. We were able to assign the Pd intermediates based on the $\mathrm{m} / \mathrm{z}$ ratio, isotope pattern (from previous work) and CID fragmentation patterns. However, the true identity of palladium intermediates, whether it is in the form of a transmetallation intermediate from the $\mathrm{n}^{\text {th }}$ cycle or in the form of an oxidative addition product in the $(n+1)^{\text {th }}$ cycle, remain unsolved in this work, since ESI-MS does not differentiate isomers. The CID fragmentation patterns indicated that both species were present in the gas-phase experiments.

Analysis of catalytic reactions is challenging even under ideal conditions. The catalyst is present in low concentration compared to reactants, products, and solvent, and it can itself manifest in different ways: precatalyst, resting state, intermediates, decomposition products, scrambling products, and more. This problem is further compounded in the case of the Suzuki polycondensation where the intermediates change identity with every turnover. Three significant 
intermediate types were observed and assigned in each stage of the catalysis, oxidative addition, transmetallation, and reductive elimination in the mass spectrum and their behaviour was observed in the chronogram normalized to the TIC. MRM has proven to be up to the task of establishing the dynamics of these species, though the usual caveats still apply: compositional information though very useful still leaves structural ambiguity. Ultimately, with the extraordinary signal-to-noise ratio and sensitivity, MRM methods are capable of obtaining high quality real-time data even on extraordinarily small amounts of material. The principle is broadly applicable to other reactions involving charged compounds.

\section{Acknowledgements}

J.S.M. thanks the NSERC Discovery program for operational funding and NSERC RTI and the University of Victoria for infrastructural support. 


\section{References}

(1) Rehahn, M.; Schlüter, A.-D.; Wegner, G.; Feast, W. J. Soluble Poly(Para-Phenylene)s. 1. Extension of the Yamamoto Synthesis to Dibromobenzenes Substituted with Flexible Side Chains. Polymer 1989, 30 (6), 1054-1059. https://doi.org/10.1016/0032-3861(89)90078-5.

(2) Sakamoto, J.; Rehahn, M.; Wegner, G.; Schlüter, A. D. Suzuki Polycondensation: Polyarylenes à La Carte. Macromolecular Rapid Communications. 2009. https://doi.org/10.1002/marc.200900063.

(3) Li, G.; Zhao, Y.; Li, J.; Cao, J.; Zhu, J.; Sun, X. W.; Zhang, Q. Synthesis, Characterization, Physical Properties, and OLED Application of Single BN-Fused Perylene Diimide. J. Org. Chem. 2015. https://doi.org/10.1021/jo502296z.

(4) Chinnappan Baskar; Yee-Hing Lai, and; Valiyaveettil*, S. Synthesis of a Novel Optically Tunable Amphiphilic Poly(p-Phenylene): Influence of Hydrogen Bonding and Metal Complexation on Optical Properties1. 2001. https://doi.org/10.1021/MA010366B.

(5) Miyaura, N.; Yamada, K.; Suzuki, A. A New Stereospecific Cross-Coupling by the Palladium-Catalyzed Reaction of 1-Alkenylboranes with 1-Alkenyl or 1-Alkynyl Halides. Tetrahedron Lett. 1979, 20 (36), 3437-3440. https://doi.org/10.1016/S00404039(01)95429-2.

(6) Miyaura, Norio.; Suzuki, Akira. Palladium-Catalyzed Cross-Coupling Reactions of Organoboron Compounds. Chem. Rev. 1995, 95 (7), 2457-2483.

https://doi.org/10.1021/cr00039a007.

(7) Suzuki, A. Cross-Coupling Reactions Of Organoboranes: An Easy Way To Construct C-C Bonds (Nobel Lecture). Angew. Chem. Int. Ed. 2011, 50 (30), 6722-6737. https://doi.org/10.1002/anie.201101379.

(8) Campeau, L.-C.; Hazari, N. Cross-Coupling and Related Reactions: Connecting Past Success to the Development of New Reactions for the Future. Organometallics 2019, 38 (1), 3-35. https://doi.org/10.1021/acs.organomet.8b00720.

(9) Suzuki, A. Carbon-Carbon Bonding Made Easy. Chem. Commun. 2005, No. 38, 47594763. https://doi.org/10.1039/B507375H.

(11) Sakamoto, J.; Rehahn, M.; Schlüter, D. Suzuki Polycondensation: A Powerful Tool for Polyarylene Synthesis. In Design and Synthesis of Conjugated Polymers; John Wiley \& Sons, Ltd, 2010; pp 45-90. https://doi.org/10.1002/9783527629787.ch2.

(12) Schlüter, A.-Dieter.; Hawker, C. J.; Sakamoto, Junji. Synthesis of Polymers : New Structures and Methods; Wiley-VCH, 2012.

(13) Rogers, M. E.; Long, T. E.; Turner, S. R. Introduction to Synthetic Methods in StepGrowth Polymers. In Synthetic Methods in Step-Growth Polymers; John Wiley \& Sons, Inc.: Hoboken, NJ, USA, 2003; pp 1-16. https://doi.org/10.1002/0471220523.ch1.

(14) Rusu, R.-D.; Schlüter, A. D. Progress in the Suzuki Polycondensation of Fluorene Monomers. RSC Adv 2014, 4 (100), 57026-57034. https://doi.org/10.1039/C4RA09710F.

(15) Schlüter, A. D. The Tenth Anniversary of Suzuki Polycondensation (SPC). J. Polym. Sci. Part Polym. Chem. 2001, 39 (10), 1533-1556. https://doi.org/10.1002/pola.1130.

(16) Dhangar, G.; Serrano, J. L.; Schulzke, C.; Gunturu, K. C.; Kapdi, A. R. PalladacycleCatalyzed Triple Suzuki Coupling Strategy for the Synthesis of Anthracene-Based OLED Emitters. ACS Omega 2017. https://doi.org/10.1021/acsomega.7b00725. 
(17) Chen, P. Electrospray Ionization Tandem Mass Spectrometry in High-Throughput Screening of Homogeneous Catalysts. Angew. Chem. Int. Ed. 2003, 42 (25), 2832-2847. https://doi.org/10.1002/anie.200200560.

(18) Iacobucci, C.; Reale, S.; Aschi, M.; Oomens, J.; Berden, G.; De Angelis, F. An Unprecedented Retro-Mumm Rearrangement Revealed by ESI-MS/MS, IRMPD Spectroscopy, and DFT Calculations. Chem. - Eur. J. 2018, 24 (27), 7026-7032. https://doi.org/10.1002/chem.201800347.

(19) Schröder, D. Applications of Electrospray Ionization Mass Spectrometry in Mechanistic Studies and Catalysis Research. Acc. Chem. Res. 2012, 45 (9), 1521-1532. https://doi.org/10.1021/ar3000426.

(20) Ray, A.; Bristow, T.; Whitmore, C.; Mosely, J. On-Line Reaction Monitoring by Mass Spectrometry, Modern Approaches for the Analysis of Chemical Reactions. Mass Spectrom. Rev. 2018, 37 (4), 565-579. https://doi.org/10.1002/mas.21539.

(21) Bächle, F.; Duschmalé, J.; Ebner, C.; Pfaltz, A.; Wennemers, H. Organocatalytic Asymmetric Conjugate Addition of Aldehydes to Nitroolefins: Identification of Catalytic Intermediates and the Stereoselectivity-Determining Step by ESI-MS. Angew. Chem. Int. Ed. 2013, 52 (48), 12619-12623. https://doi.org/10.1002/anie.201305338.

(22) Markert, C.; Pfaltz, A. Screening of Chiral Catalysts and Catalyst Mixtures by Mass Spectrometric Monitoring of Catalytic Intermediates. Angew. Chem. 2004, 116 (19), 2552-2554. https://doi.org/10.1002/ange.200453844.

(23) Vikse, K.; Khairallah, G. N.; McIndoe, J. S.; O’Hair, R. A. J. Fixed-Charge Phosphine Ligands to Explore Gas-Phase Coinage Metal-Mediated Decarboxylation Reactions. Dalton Trans. 2013, 42 (18), 6440. https://doi.org/10.1039/c3dt32285h.

(24) Crawford, E.; Lohr, T.; Leitao, E. M.; Kwok, S.; Mcindoe, J. S. Distannoxane Speciation during Esterification Catalysis: Revealing Insights Provided by Electrospray Ionization Mass Spectrometry. Dalton Trans. 2009, No. 42, 9110. https://doi.org/10.1039/b913492a.

(25) Vikse, K. L.; Henderson, M. A.; Oliver, A. G.; McIndoe, J. S. Direct Observation of Key Intermediates by Negative-Ion Electrospray Ionisation Mass Spectrometry in PalladiumCatalysed Cross-Coupling. Chem. Commun. 2010, 46 (39), 7412. https://doi.org/10.1039/c0cc02773a.

(26) Vikse, K. L.; McIndoe, J. S. Mechanistic Insights from Mass Spectrometry: Examination of the Elementary Steps of Catalytic Reactions in the Gas Phase. Pure Appl. Chem. 2015, 87 (4), 361-377. https://doi.org/10.1515/pac-2014-1118.

(27) Vikse, K.; Naka, T.; McIndoe, J. S.; Besora, M.; Maseras, F. Oxidative Additions of Aryl Halides to Palladium Proceed through the Monoligated Complex. ChemCatChem 2013, 5 (12), 3604-3609. https://doi.org/10.1002/cctc.201300723.

(28) Vikse, K. L.; Ahmadi, Z.; Manning, C. C.; Harrington, D. A.; McIndoe, J. S. Powerful Insight into Catalytic Mechanisms through Simultaneous Monitoring of Reactants, Products, and Intermediates. Angew. Chem. Int. Ed. 2011, 50 (36), 8304-8306. https://doi.org/10.1002/anie.201102630.

(29) Ahmadi, Z.; Oliver, A. G.; McIndoe, J. S. An Unexpected Pathway for Ligand Substitution in an Aryl Halide Complex of Palladium. ChemPlusChem 2013, 78 (7), 632635. https://doi.org/10.1002/cplu.201300131.

(30) Vikse, K. L.; Woods, M. P.; McIndoe, J. S. Pressurized Sample Infusion for the Continuous Analysis of Air- and Moisture-Sensitive Reactions Using Electrospray 
Ionization Mass Spectrometry. Organometallics 2010, 29 (23), 6615-6618. https://doi.org/10.1021/om1008082.

(31) Vikse, K. L.; Ahmadi, Z.; Luo, J.; van der Wal, N.; Daze, K.; Taylor, N.; McIndoe, J. S. Pressurized Sample Infusion: An Easily Calibrated, Low Volume Pumping System for ESI-MS Analysis of Reactions. Int. J. Mass Spectrom. 2012, 323-324, 8-13. https://doi.org/10.1016/j.ijms.2012.03.007.

(32) Gross, J. H. Electrospray Ionization. In Mass Spectrometry; Springer International Publishing: Cham, 2017; pp 721-778. https://doi.org/10.1007/978-3-319-54398-7_12.

(33) Gross, J. H. Tandem Mass Spectrometry. In Mass Spectrometry; Springer International Publishing: Cham, 2017; pp 539-612. https://doi.org/10.1007/978-3-319-54398-7_9.

(34) Rusu, R.-D.; Schlüter, A. D. Progress in the Suzuki Polycondensation of Fluorene Monomers. RSC Adv. 2014, 4 (100), 57026-57034. https://doi.org/10.1039/C4RA09710F.

(35) Zhang, K.; Tkachov, R.; Ditte, K.; Kiriy, N.; Kiriy, A.; Voit, B. AB- Versus AA+BBSuzuki Polycondensation: A Palladium/Tris(Tert-Butyl)Phosphine Catalyst Can Outperform Conventional Catalysts. Macromol. Rapid Commun. 2020, 41 (1), 1900521. https://doi.org/10.1002/marc.201900521.

(36) Sugita, H.; Ohta, Y.; Yokozawa, T. Synthesis of Cyclic Aromatic Polymer Containing Thiophene or Pyridine by Means of Unstoichiometric Suzuki-Miyaura Cyclic Polycondensation: Effect of the Position of Bromine of Heteroarylenes on Cyclic Polycondensation. J. Polym. Sci. 2020, 58 (9), 1236-1240.

https://doi.org/10.1002/pol.20200036.

(37) Sugita, H.; Nojima, M.; Ohta, Y.; Yokozawa, T. Unstoichiometric Suzuki-Miyaura Cyclic Polymerization of Extensively Conjugated Monomers. Polym. Chem. 2019, 10 (10), 1182-1185. https://doi.org/10.1039/C8PY01741G.

(38) Pentsak, E. O.; Eremin, D. B.; Gordeev, E. G.; Ananikov, V. P. Phantom Reactivity in Organic and Catalytic Reactions as a Consequence of Microscale Destruction and Contamination-Trapping Effects of Magnetic Stir Bars. ACS Catal. 2019, No. 9, 30703081. https://doi.org/10.1021/acscatal.9b00294.

(39) Yunker, L. P. E.; Ahmadi, Z.; Logan, J. R.; Wu, W.; Li, T.; Martindale, A.; Oliver, A. G.; McIndoe, J. S. Real-Time Mass Spectrometric Investigations into the Mechanism of the Suzuki-Miyaura Reaction. Organometallics 2018, 37 (22), 4297-4308. https://doi.org/10.1021/acs.organomet.8b00705.

(40) Henderson, W.; McIndoe, J. S. Mass Spectrometry of Inorganic, Coordination and Organometallic Compounds; John Wiley \& Sons, Ltd: Chichester, UK, 2005. https://doi.org/10.1002/0470014318.

(41) Vikse, K. L.; Henderson, M. A.; Oliver, A. G.; McIndoe, J. S. Direct Observation of Key Intermediates by Negative-Ion Electrospray Ionisation Mass Spectrometry in PalladiumCatalysed Cross-Coupling. Chem. Commun. 2010, 46 (39), 7412-7414. https://doi.org/10.1039/C0CC02773A.

(42) Vikse, K. L.; Ahmadi, Z.; Manning, C. C.; Harrington, D. A.; McIndoe, J. S. Powerful Insight into Catalytic Mechanisms through Simultaneous Monitoring of Reactants, Products, and Intermediates. Angew. Chem. Int. Ed. 2011, 50 (36), 8304-8306. https://doi.org/10.1002/anie.201102630.

(43) Qian, R.; Liao, Y.-X.; Guo, Y.-L.; Guo, H. ESI-FTICR-MS Studies on Gas Phase Fragmentation Reactions of $\operatorname{ArPd}(\mathrm{PPh} 3) 2 \mathrm{I}$ Complexes. J. Am. Soc. Mass Spectrom. 2006, 17 (11), 1582-1589. https://doi.org/10.1016/j.jasms.2006.07.009. 
(44) Leclerc, M.; Morin, J.-F. Synthetic Methods for Conjugated Polymers and Carbon Materials; Wiley-VCH, 2017.

(45) Agrawal, D.; Zins, E.-L.; Schröder, D. Intramolecular Scrambling of Aryl Groups in Organopalladium Complexes [ArPd(PPh3)2]+: From Solution to the Gas Phase, Back Again, and In-Between. Chem. - Asian J. 2010, 5 (7), 1667-1676. https://doi.org/10.1002/asia.201000086.

(46) Agrawal, D.; Schröder, D. Insight into Solution Chemistry from Gas-Phase Experiments †. Organometallics 2011, 30 (1), 32-35. https://doi.org/10.1021/om100972n.

(47) Domon, B.; Aebersold, R. Mass Spectrometry and Protein Analysis. Science 2006, 312 (5771), 212-217. https://doi.org/10.1126/science.1124619.

(48) Norris, A. J.; Whitelegge, J. P.; Faull, K. F.; Toyokuni, T. Analysis of Enzyme Kinetics Using Electrospray Ionization Mass Spectrometry and Multiple Reaction Monitoring: Fucosyltransferase V †. Biochemistry 2001, 40 (13), 3774-3779. https://doi.org/10.1021/bi010029v.

(49) Carr, S. A.; Anderson, L. Protein Quantitation through Targeted Mass Spectrometry: The Way Out of Biomarker Purgatory? Clin. Chem. 2008, 54 (11), 1749-1752. https://doi.org/10.1373/clinchem.2008.114686.

(50) Wang, Y.; Lin, W.-Y.; Liu, K.; Lin, R. J.; Selke, M.; Kolb, H. C.; Zhang, N.; Zhao, X.-Z.; Phelps, M. E.; Shen, C. K. F.; Faull, K. F.; Tseng, H.-R. An Integrated Microfluidic Device for Large-Scale in Situ Click Chemistry Screening. Lab. Chip 2009, 9 (16), 2281. https://doi.org/10.1039/b907430a.

(51) Khanal, D. D.; Baghdady, Y. Z.; Figard, B. J.; Schug, K. A. Supercharging and Multiple Reaction Monitoring of High-molecular-weight Intact Proteins Using Triple Quadrupole Mass Spectrometry. Rapid Commun. Mass Spectrom. 2019, 33 (9), 821-830. https://doi.org/10.1002/rcm.8418.

(52) Thomas, G. T.; Janusson, E.; Zijlstra, H. S.; McIndoe, J. S. Step-by-Step Real Time Monitoring of a Catalytic Amination Reaction. Chem. Commun. 2019, 55 (78), 1172711730. https://doi.org/10.1039/C9CC05076K.

(53) Goodson, F. E.; Wallow, T. I.; Novak, B. M. Application of "Transfer-Free" Suzuki Coupling Protocols toward the Synthesis of "Unambiguously Linear" Poly(p-Phenylenes). Macromolecules 1998, 31 (7), 2047-2056. https://doi.org/10.1021/ma9717294. 